\title{
Ev Dışı Gıda Tüketim Sınıflarının Yapay Sinir Ağları İle Tahmin Edilmesi (Estimating Out-Of-Home Food Consumption Classes Using Artificial Neural Networks)
}

\section{Uğur ERCAN iD a}

a Akdeniz Üniversitesi, Enformatik Bölümü, Antalya, Türkiye. ugurercan@akdeniz.edu.tr

\section{MAKALE BİLGİSI \\ Anahtar Kelimeler: \\ Ev dışı gıda tüketimi Hanehalkı bütçe anketi Yapay sinir ağları Sinıflandirma}

Gönderilme Tarihi 8 Temmuz 2021

Revizyon Tarihi 1 Aralık 2021 Kabul Tarihi 10 Aralık 2021

Makale Kategorisi: Araştırma Makalesi

\section{ÖZET}

Amaç - Gerçekleştirilen araştırmanın amacı, Türkiye hanehalkı ev dışı gıda tüketim sınıflarının tahmin edilmesidir.

Yöntem - Çalışmada kullanılan veriler Türkiye İstatistik Kurumu tarafından derlenen Hanehalkı Bütçe Anketine aittir. 2019 yılına ait toplam 11.521 hanehalkından elde edilen veriler çalışmanın analizinde kullanılmıştır. Ev dışı gıda tüketim sınıfının belirlenmesinde Yapay Sinir Ağları yöntemi kullanılmıştır.

Bulgular - Yapay Sinir Ağları yönteminde, hanelerin \%70'i kullanılarak modelin eğitimi gerçekleştirilmiş, kalan \%30'u ise test aşaması için ayrılmıştır. İkili sınıflandırma problemlerinin değerlendirilmesinde kullanılan karșıtlık matrisi ile bu matristen elde edilen metrikler ile kurulan modelin performansı ölçülmüştür. Model eğitim aşamasında \%73.12, test aşamasında ise \%73.39 doğruluk oranına sahiptir. Modelin duyarlığı eğitim aşamasında \%77.28, test aşamasında ise \%80.39'dir. Modelin kesinliği test aşamasında \%71.22, test aşamasında ise \%69.73'dür. Metrikler ve metriklere ait yorumlar bulgular kısmında detaylı bir şekilde açıklanmıştır. Kurulan modelin eğitim ve test aşaması sonuçlarından hesaplanan metrikler incelendiğinde sistemin doğru ve tutarlı sonuçlar elde ettiği görülmüştür.

Tartışma - Literatürde incelenen çalışmalardan elde edilen değişkenlerin haricinde modele eklenen değişkenlerin, kurulan Yapay Sinir Ağları modelinin sınıflandırma doğruluğunu arttırdığı görülmüştür. Türkiye hanehalkı ev dışı gıda tüketimi ile yapılan çalışmaların tamamına yakını ekonometrik modeller kullanılarak gerçekleștirilmiştir. Eklenen yeni değișkenler ile kurulacak ekonometrik modellerin, daha önce elde edilen modellerin sonuçlarını değiştireceği düşünülmektedir. Yapay Sinir Ağları yöntemi kullanılarak Türkiye hanehalkı ev dışı gıda tüketim sınıfının tahmin edilmesine yönelik literatürde bir çalışmaya rastlanılmamış olması nedeniyle gerçekleştirilen çalışmanın literatüre katkı sağlayabileceği düşünülmektedir.

\section{ARTICLE INFO}

\section{ABSTRACT}

\section{Keywords:}

Out-of-home consumption

Household budget survey Artificial neural networks Classification

Received 8 July 2021 Revised 1 December 2021 Accepted 10 December 2021

Article Classification: Research Article
Purpose - The purpose of the research carried out is to estimate out-of-home food consumption classes of food Turkish households.

Design/methodology/approach - The data used in this study were derived from the Household Budget Survey gathered by the TURKSTAT. The data obtained from a total of 11,521 households in 2019 were used in the analysis. Artificial Neural Networks (ANN) technique were used to determine out-of-home food consumption classes.

Results - In the ANN method, $70 \%$ of the households were used to be trained for the model, and the remaining 30\% were allocated for the test phase. The evaluation of binary classification problems and the performance of the model established were evaluated with the confusion matrix and the metrics obtained from this matrix. The model has an accuracy rate of $73.12 \%$ in the training phase and $73.39 \%$ in the testing phase. The sensitivity of the model is $77.28 \%$ in the training phase and $80.39 \%$ in the testing phase. The precision of the model is $71.22 \%$ in the testing phase and $69.73 \%$ in the testing phase. The metrics and comments on the metrics are explained in detail in the findings section. When the metrics calculated from the training and testing phase results of the established model were examined, it was seen that the system obtained correct and consistent results.

Discussion - Apart from the variables obtained from the studies examined in the literature, it has been seen that the variables added to the model increase the classification accuracy of the established Artificial Neural Networks model. Almost all of the studies conducted in household out-of-food consumption in Turkey was carried out using econometric models. It is thought that the econometric models to be established with the new variables added will change the results of the previously obtained models. There's no study that could be found in the literature that carried out to estimate household out-of-home food consumption classes using ANN method in Turkey. For this reason, this study makes an original contribution to the literature.

\section{Önerilen Atıf/Suggested Citation}

Ercan, U. (2021). Ev Dışı Gıda Tüketim Sınıflarının Yapay Sinir Ağları İle Tahmin Edilmesi, İşletme Araştırmaları Dergisi, 13 (4), $3265-$ 3277 . 


\section{Giriş}

Artan gelirler, kentleşme, küreselleşme, kadınların iş gücüne girmesi ve diğer çeşitli nedenlerden dolayı hazır ve paketlenmiş yemekler ile ev dışında tüketilen gıda ürünleri, hanehalkının gıda bütçesinden giderek artan bir pay almakta, bununla beraber tüketim kalıpları gelişmekte olan dünyada hızla değişim göstermektedir. 20. yüzyılın son on yıllarında başlayan beslenme dönüşümü ile tüketici davranışları önemli bir eğilim göstermiş, evde gıda harcamalarının payı azalırken, ev dışı gıda tüketimini artmıştır (Gül vd., 2007, s. 32; Smith vd., 2014, s. 20; Farfán vd., 2017, s. 146).

İngiltere' de gerçekleştirilen bir araştırmaya göre yetişkinlerin \%27.1'i ve çocukların \%19'unun haftada bir veya daha fazla sayıda dışarıda yemek tükettiği görülürken, yetişkinlerin \%21.1'i ve çocukların \%21'inin haftada bir veya daha fazla sayıda evde paket yemek tükettiği görülmüştür (Adams vd., 2015, s. 1). ABD'de ev dışı gıda harcamaları, 2010 yılında ilk kez evde gıda harcamalarını aşarak, toplam gıda harcamaları içindeki payını 1987'de \%44'ten 2010'da \%50.2'ye yükselttiği görülmüştür (Saksena vd., 2018, s. VIII). ABD'de yetişkinlerin \%50'sinden fazlasının haftada en az üç defa, \%35'inden fazlasının ise en az iki defa hazır yiyecek tükettiği görülmüştür (Kant vd., 2015, s. 820). Kentsel Çin'de, 1995-2001 yılları arasında, evde tüketilen gidaya harcanan payı \%90'dan \%84'e düşerken, ev dışı gıda harcamalarının payı \%10'dan \%16'ya yükselmiştir. Böylece, evde gıda harcamaları \%5 azalırken, ev dışı gıda harcamaları harcamalarının \%63 arttığı görülmüştür (Ma vd., 2006, s. 105). Dünya genelinde meydana gelen hızlı değişimler Türk toplumunu da etkilemiştir. Yapısal, sosyal değişimler, yaşam tarzının ve kurallarının değişmesi ile beraber insanların ve ailelerin tüketim alışkanlıkları da değişmiştir. Son yıllarda, özellikle büyük şehirlerde başta olmak üzere bütün il merkezleri ile bazı ilçe merkezlerinde pizza ve hamburger gibi gıda ürünlerini satan batı kökenli işletmelerin sayısının belirgin bir şekilde artması bunun en önemli göstergesidir (Akbay ve Boz, 2005, s. 122; Gül vd., 2007, s. 33).

Literatür kısmında detayları belirtilen çalı̧̧maların neredeyse tamamı ev dışı gıda tüketimine etki eden faktörlerin belirlenmesine yöneliktir. Gerek uluslararası gerek ulusal literatürde gerçekleştirilen bu Çalışmalarda Logit/Probit Regresyon, Multinomial Logit Regresyon, Working-Leser, Double Hurdle, Tobit Model, Poisson ve Negatif Binom Regresyon gibi ekonometrik modeller kullanılmıştır (Dong vd. 2000; Akbay ve Boz, 2005; Bamiro, 2012; Mottaleb vd., 2017; Zang vd., 2018; Demirel ve Hatırlı, 2020). Gerçekleştirilen çalışmanın amacı, Türkiye hanehalkı ev dışı gıda tüketim sınıflarının Yapay Sinir Ağları (YSA) ile tahmin edilmesidir. Çalışmada, özellikle son 20 yıldır giderek artan bir popülariteye sahip olan makine öğrenmesi yöntemlerinden YSA modeli kullanılmıştır. YSA yöntemi kullanılarak Türkiye hanehalkı ev dışı gıda tüketim sınıflarının tahmin edilmesine yönelik literatürde gerçekleştirilen bir çalışmaya rastlanılmamış olmasından dolayı bu çalışmanın literatüre özgün bir katkı sağlayabileceği düşünülmektedir. Çalışmada ayrıca, kavramsal çerçeve başlı̆̆ı altında detayları belirtilen ve literatürden bağımsız olarak modele eklenen değişkenlerin hanehalkı ev dışı gıda tüketimi üzerinde etkinliği araştırılacaktır.

Çalışma giriş, kuramsal çerçeve, yöntem, bulgular, sonuç ve tartışma olmak üzere beş bölümden oluşmaktadır.

\section{Kavramsal Çerçeve}

Hanehalkı ev dışı gıda tüketimi ile ilgili veri tabanlarından son 20 yıla ait seçilen 15 çalışmaya ait detaylar literatür olarak verilmiştir. Çalmaşur ve Daştan (2020) Erzurum'da hanelerin ev dışı gida tüketimini etkileyen faktörleri belirlemişlerdir. 2019 yılında, 400 haneden derlenen verilerin analizinde ki-kare ve logit regresyon modeli kullanmışlardır. Çalışmanın sonuçlarına göre; gelir, öğrenim gören birey sayısı, çocuk sayısı, hanehalkı büyüklüğü, meslek ve eşin mesleği ev dışı gıda tüketimini etkilemektedir.

Demirel ve Hatırlı (2020) Türkiye'de hanelerin ev dışı gıda tüketim alışkanlıklarını etkileyen faktörleri belirlemişlerdir. TÜİK Hanehalkı Bütçe Araştırması 2017 verilerini logit regresyon yöntemi ile analiz etmişlerdir. Çalışmanın sonuçlarına göre; hanehalkı tipi, hanehalkı büyüklüğü, hanehalkı reisinin çalışma durumu ile otomobil sahipliğinin hanehalkı ev dışı gıda tüketim alışkanlığında pozitif etkili olduğu görülürken, hanehalkı reisinin medeni durumu (evli), hane aylık gelirinin düşük ve orta gelir grubunda olması ile hanehalkının pazar alışkanlığı olmasının hanehalkı ev dışı gıda tüketim alışkanlığında negatif etkili olduğu görülmüştür.

Gönül ve Karlı (2020) Antalya'da farklı gelir gruplarındaki hanelerin ev dışı gıda tüketimine yönelik tutum ve davranışlarını analiz etmişlerdir. 384 kişiden derlenen verilerin analizinde ki-kare ve tanımlayıcı istatistikler 
kullanılmıştır. Çalışmanın sonucuna göre hanelerin ev dışı gıda tüketim tercih etme nedenlerinin; lezzetli olması, arkadaşları ile iyi vakit geçirme, farklı ortamlarda yemek yeme isteği, çocukların tercih etmesi, ekonomik olması, besin değerinin yüksek olması ve alışkanlık olduğu görülmüştür. Ev dışı gıda tüketiminde ailenin karar vermesinde en etkili bireyin çocuklar olduğu tespit edilmiştir.

Andrade vd. (2018) Brezilya'da ev dışı yiyecek davranışlarını incelemişlerdir. 2008-2009 yılı Bireysel Gıda Anketine ait 34.003 kişiden derlenen verilerin analizinde faktör analizi ve doğrusal regresyon analizi kullanılmıştır. Yaş, cinsiyet, gelir, eğitim düzeyi, kır-kent durumu, gelir ve bölge değişkenlerinin ev dişı yiyecek tüketim davranışlarını etkilediği görülmüştür.

Janssen vd. (2018) paket servis ve hazır yemek tüketiminin belirleyicileri için bir inceleme çalışması yapmışlardır. Sosyal etki, biyolojik ve sosyolojik dürtüler, yaş grubu, etnik köken ve cinsiyet gibi değişkenlerin paket servis ve hazır yemek tüketimini etkilediği görülmüştür.

Zang vd. (2018) Şangay'da ev dışı gıda tüketiminin belirleyicilerini incelemişlerdir. 2012-2013 Şangay Diyet ve Sağlık Araştırmasına ait 1.689 kişiden elde edilen veriler çalışmada kullanılmıştır. Tanımlayıcı istatistikler, tek değişkenli ve çok değişkenli lojistik regresyon modellerinin kullanıldığı çalışmanın sonuçlarına göre; gelir, cinsiyet, yaş, medeni durum, eğitim seviyesi, meslek grubu, hanehalkı büyüklüğü (yalnızca üç kişilik aile), bölge, sigara ve alkol tüketme durumunun ev dışı gıda tüketiminde etkili olduğu görülmüştür. Yüksek sosyoekonomik statü ve kentsel yerleşim, evden uzakta yemeklerin daha fazla tüketilmesiyle ilişkilendirildi.

Mottaleb vd. (2017) ev dışı gıda tüketim seçimlerini ve harcamalarını incelemişlerdir. 2000, 2005, 2010 yıllarına ait Bangladeş Gelir ve Harcama Anketi'nden elde edilen 29.648 hanehalkına ait veriler çalışmada kullanılmıştır. Double Hurdle regresyon modelinin kullanıldığı çalışmanın sonuçlarına göre; kır-kent durumu, gelir, hanehalkı büyüklüğü, hanehalkı reisinin yaşı, eğitim düzeyi ve cinsiyetinin ev dışı gıda tüketimini etkilediği görülmüştür.

Kutluay Tutar ve Yazırlı (2016) hanelerin ev dışı gıda tüketimini etkileyen faktörleri belirlemişlerdir. 2015 yılında, Nazilli ilçesinde yaşayan 230 haneden derledikleri verilerin analizinde tanımlayıcı istatistikler kullanılmıştır. Çalışmanın sonuçlarına göre, gelir, medeni durum, annenin çalışma durumu ve eğitim seviyesi ile hanelerin mal varlıklarının ev dışı gıda tüketiminde etkili olduğu görülmüştür.

Liu vd. (2015) Çin'in kentsel bölgelerindeki ev dışı gıda tüketimini sosyoekonomik ve sosyodemografik değişkenler açısından analiz etmişlerdir. 2007, 2009, 2010 ve 2011 yıllarında 1.340 haneden derlenen verilerin analizinde tanımlayıcı istatistikler ve double hurdle modeli kullanılmıştır. Çalışmanın sonuçlarına göre; gelir, hanehalkı yaş kompozisyonu, hanehalkı reisinin eşinin eğitim düzeyinin ev dışı gıda tüketimini etkilediği görülmüştür.

Drescher ve Roosen (2013) Almanya'daki hanelerin 25 yıllık, evde ve ev dışı gıda tüketim verilerinin kohort analizini incelemişlerdir. Almanya Gelir ve Tüketim Anketinden elde edilen 265.699 hanehalkına ait verilerin kullanıldığı çalışmada Görünüşte İlişkisiz Regresyon modeli kullanılmıştır. Çalışmanın sonuçlarına göre; gelir, cinsiyet, yaş, meslek, hanehalkı kompozisyonu ve büyüklüğü ile bölge değişkenlerinin ev dışı gıda tüketimi üzerinde etkileri olduğu görülmüştür.

Bamiro (2012) Nijerya'da ev dışı gıda tüketiminin belirleyicilerini araştırmışlardır. 80 kişiden derlenen verilerin analizinde tanımlayıcı istatistikler, probit ve tobit regresyon modelleri kullanılmıştır. Çalışmanın sonuçlarına göre ev dışı gıda tüketiminin cinsiyet, hanehalkı büyüklüğü ve kompozisyonundan etkilendiği görülmüştür.

Fanning vd. (2010) ABD'deki hazır yemek tüketiminin belirleyicilerini incelemişlerdir. 1994-1996 Bireysel Gıda Alım Anketi ve 1998 Tamamlayıcı Çocuk Anketinden elde edilen 21.662 gözleme ait verilerin analizinde tanımlayıcı istatistikler ve lojistik regresyon modeli kullanılmıştır. Çalışmanın sonuçlarına göre; gelir, yaş, cinsiyet, bölge ve hanehalkı büyüklüğünün hazır yemek tüketimini etkilediği görülmüştür.

Fabiosa (2008) Mısır'da ev dışı gıda tüketiminin belirleyicilerini tahmin etmiştir. 1997 yılına ait Mısır Entegre Hanehalkı Anketinden elde edilen 2.500 haneye ait veriler çalışmada kullanılmıştır. Tanımlayıcı istatistikler ve Tobit modelin kullanıldığı çalışmanın sonuçlarına göre; kır-kent, hanehalkı büyüklüğü, hanehalkı reisinin yaşı ve cinsiyeti, gelirin ev dışı gıda tüketimini etkilediği görülürken hanehalkı reisinin medeni durumunun etkisi görülmemiştir. 
Akbay ve Boz (2005) Kahramanmaraş kentsel alanda ailelerin ev ve ev dışı gıda tüketim yapılarını analiz edilmiştir. 2003 yılında, 240 haneden derlenen verilerin analizinde Working-Leser modeli kullanılmıştır. Çalışmanın sonuçlarına göre gelir, ebeveynlerin yaşı ve eğitimi, çalışan fert sayısı ve annenin çalışmasının ev dışı gıda tüketimini etkilediği görülmüştür.

Dong vd. (2000) ev dişı gıda tüketim sıklığına etki eden sosyo-demografik belirleyicileri incelemişlerdir. Ulusal Panel Günlüğü anketine ait 1982-1989 yılları arasında 34.708 haneden derlenen verilerin analizinde Poisson ve Negatif Binom Regresyon modelleri kullanılmıştır. Çalışmanın sonuçlarına göre ev dışı gıda tüketim sıklığının belirleyicileri; hanehalkı reisi, ırk, eğitim, cinsiyet, bölge, yaş, mevsimsellik ve hafta sonu yemeği değişkenleridir.

Litaratür kısmında incelenen çalışmalardan elde edilen bulgular neticesinde hanehalkına ait fert ve hanehalkı karakteristikleri (gelir, hanehalkı büyüklügü̈, hanehalkı reisinin yaşı, cinsiyeti, eğitim düzeyi, çalışma durumu, medeni durumu ve sigorta durumu, hanehalkı kompozisyonu, hanede öğrenci varlığı, hanede yaşlı birey varlığ $1\left(60+\right.$ yaş), hanede $0-5$ yaş birey varlığ $\breve{l}_{1}$ YSA modelinde kullanılmıştır. Bunun yanı sıra detayları Tablo 1'de gösterilen, hanehalkına ve hane fertlerine ait bazı değişkenler (hanenin pazar alışkanlı̆̆ı, hanenin toplu taşıma ve alış veriş merkezlerine erişim durumu, hanede alkol ve sigara tüketimi, hanede internet kullanımı, hanenin internetten alış veriş yapma durumu, özel sigorta sahipliği, kredi kartı sahipliği, hanede spor yapma alışkanlığı vb.) ev dışı gıda tüketimi yapan ve yapmayan hanelerin tespitinde önemli olabileceği düşüncesiyle YSA modeline dâhil edilmiştir.

\section{Yöntem}

Yöntem başlığı altında üç alt başlık kullanılmıştır. Bunlardan birincisi çalışmada kullanılan model olan YSA ile ilgili bilgilerin yer aldığı kısım, ikincisi çalışmada kullanılan veri seti ile ilgili temel bilgiler ve istatistiklerin yer aldığı kısım, üçüncüsü ise verilerin analizinin yapıldığı platform ve modellemeden elde sonuçların değerlendirmesi ile ilgili bilgilerin yer aldığı bölümdür.

\subsection{Araştırmanın Modeli}

Gerçekleştirilen çalışmada Türkiye hanehalkı ev dışı gıda tüketim sınıflarının YSA ile tahmin edilmesi amacıyla veri madenciliği temelli bir model oluşturulmuştur. Veri madenciliği kavramının literatürde birçok kez tanımı yapılmıştır. Kapsamlı bir tanım yapılacak olursa, veriler arasında istatistiksel ve klasik metotlarla bulunamayan ilişkileri ve örüntüleri ortaya çıkarmak için istatistik, matematik, makine öğrenimi, veri tabanı ve bilgisayar uygulamaları alanlarının birleşimi tekniklerin kullanılarak analiz edilmesi, sonuçların görselleştirilmesi ve özetlenmesi süreci olarak tanımlanabilir (Irmak, 2009, s. 5).

Veri Madenciliği sürecinde kullanılan modeller, tahmin edici ve tanımlayıcı olmak üzere iki ana başlık altında incelenmektedir. Sonuçları bilinen verilerden hareketle bir model geliştirilip ve kurulan bu model vasıtasıyla sonuçları bilinmeyen değerlerin tahmin edilmesinin amaçlandığı modeller tahmin edici modeller olarak isimlendirilirken, tanımlayıcı modellerde ise amaç karar vermeye rehberlik etmede kullanılabilecek mevcut verilerdeki örüntülerin, desenlerin tanımlanmasını sağlamaktır (Akpınar, 2000, s. 5). Sınıflandırma ve Regresyon Modelleri tahmin edici, Kümeleme Analizi, Birliktelik Kuralları ve Ardışık Zamanlı Örüntüler ise tanımlayıcı modellerdir (Ayık vd., 2007, s. 444). Gerçekleştirilen çalışma bir sınıflandırma problemi olarak ele alındığı için Yapay Sinir Ağları (YSA) denetimli bir öğrenme modeli olarak kullanılmıştır.

Sınıflandırma, zaman serisi analizi, tahmin ve kümeleme gibi birçok alandaki problemlerin çözümünde kullanılan YSA, başta mühendisler, uygulamalı matematikçiler, finansçılar olmak üzere endüstri, işletme, bilim ve tıp alanlarında araştırmacılar tarafından sıklıkla tercih edilmektedir (Fausett, 1994, s. 2; Berry ve Linoff, 2004, s. 211; Zhang, 2010, s. 419). Bununla birlikte, yüksek gürültülü verilere toleransları (sağlam olmaları=robust), eğitim görmedikleri (yani alışkın olmadıkları) kalıpları sınıflandırma yetenekleri, nitelikler ve sınıflar arasındaki ilişkiler hakkında çok az bilgiye sahip olduğunda kullanılabilir olması nedeniyle tercih edilen YSA, çoğu karar ağacı algoritmasının aksine, sürekli değerli girdi ve çıktılar için de oldukça uygundurlar (Han vd., 2011, s. 398). Doğrusal olmayan verileri iyi açıklama yeteneğinin varlığı YSA' ların sahip olduğu bir diğer büyük avantajdır (Yücesan, 2018, s. 695). Bilgiyi çevreden alan, alınan bilgiyi depolayabilen ve gerektiğinde kullanabilen YSA'lar (Yakut vd., 2015, s. 176) insan beyninin bilgiyi işleme ve saklama şeklini taklit etmeye çalışan bir bilgisayar sistemidir ve nöron adı verilen matematiksel işlem birimleri arasında bağlantılar oluşturarak çalışır (Skias, 2006, s. 1). Nöronlar birbirine ağırlıklı bağlantılarla birbirine 
bağlanır ve katmanlar halinde düzenlenir. Bir katmanda yer alan nöron kendinden önceki ve sonraki katmanın nöronlarına bağlanır (Giudici, 2003, s. 107). YSA'da yer alan nöronların genel yapısı Şekil 1'de gösterilmektedir.

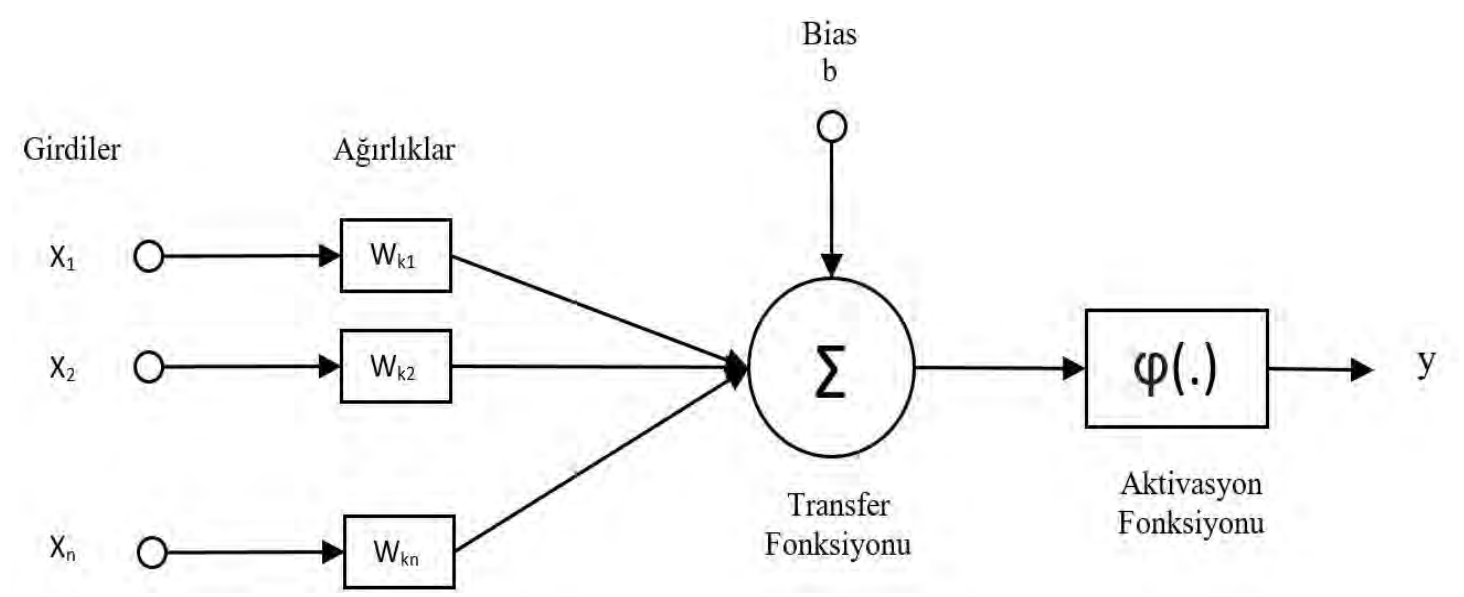

Şekil 1. Nöron yapısı Kaynak: Haykin, 2008, s. 11

Nöronlar arasındaki bağlantılar, bağlı nöronlar arasındaki nedensel ilişkiyi belirtir ve ağırlıklar uyarlanabilirdir (Kantardzic, 2019, s. 232). Ağırlıklar uygun bir öğrenme algoritmasına göre ağ üzerinde hareket eden çeşitli sinyallere yanıt olarak değiştirilen uyarlanabilir katsayılardır (Giudici, 2003, s. 107).

Girişler, $\mathrm{x}_{\mathrm{i}}$, nöronlardan veya veri setinden alınır ve bir toplama fonksiyonu ile birleştirilir, daha sonra genellikle doğrusal olmayan bir aktivasyon fonksiyonuna gönderilerek elde edilen çıkış yanıtı, y, diğer nöronlara yönlendirilir (Larose, 2005, s. 129). Her nöron bir çıkış sinyali üretir. Tüm giriş sinyalleri aynı anda nörona ulaşır, bu nedenle nöron birden fazla giriş sinyali alır, ancak yalnızca bir çıkış sinyali üretir. Her giriş sinyali bir bağlantı ağırlığı ile ilişkilidir. Ağırlıklar, giriş sinyalinin nöron tarafından iletilen sonuç sinyalini üretmedeki sahip olabileceği göreceli önemi belirler (Giudici, 2003, s. 107).

Bias olarak adlandırılan bir eşik değeri genellikle girdi olarak kullanılır ve regresyon modelindeki sabit ile benzer bir yapıdadır (Irmak, 2009, s. 59-60). Gerçekleştirilen çalışma bir sınıflandırma problemi olarak ele alındığı için Yapay Sinir Ağları denetimli bir öğrenme modeli olarak kullanılmıştır (Larose, 2005, s. 135). YSA'da öğrenme genelde geri yayılım algoritması adı verilen bir algoritma ile gerçekleştirilir (Lavrač ve Zupan, 2010, s. 1124).

\subsection{Veri Seti}

Gerçekleştirilen çalışmada Türkiye İstatistik Kurumu tarafından derlenen, Hanehalkı Bütçe Anketi verileri kullanılmıştır. 2019 yılına ait toplam 11.521 hanehalkına ait veriler çalışmanın analizinde kullanılmıştır (TÜİK, 2019). Çalışmada gelir ve diğer harcama değişkenlerine ait veriler, Aralık 2019 tarihine göre enflasyondan arındırılmıştır. Literatür kısmında incelenen makalelerden elde edilen bilgiler doğrultusunda, 37 değişken YSA modeline girdi değişkeni olarak verilirken, hanenin ev dişı gıda harcaması yapma durumu (0-Hane ev dışı gıda harcaması yapmadı, 1-Hane ev dışı gıda harcaması yaptı) çıktı değişkeni olarak belirlenmiştir. (TÜIK, 2019). Çalışmada kullanılan hanelere ait tanımlayıcı istatistikler Tablo 1'de gösterilmiştir.

Tablo 1. Tanımlayıcı istatistikler

\begin{tabular}{llrr}
\hline Karakteristik & Açıklaması & Frekans & Yüzde \\
\hline \multirow{2}{*}{ Ev dışı gıda tüketim yapma durumu } & Yapıyor & 5.706 & 49.53 \\
& Yapmiyor & 5.815 & 50.47 \\
Hanehalkı reisinin cinsiyeti & Erkek & 8.841 & 76.74 \\
& Kadın & 2.680 & 23.26 \\
& $17-29$ & 705 & 6.12 \\
Hanehalkı reisinin yaşı & $30-44$ & 3.398 & 29.49 \\
& $45-59$ & 3.837 & 33.30 \\
Hanehalkı reisinin eğitim düzeyi & 60 ve üzeri & 3.581 & 31.08 \\
& Eğitimsiz & 1.521 & 13.20
\end{tabular}


U. Ercan 13/4 (2021) 3265-3277

\begin{tabular}{|c|c|c|c|}
\hline Karakteristik & Açıklaması & Frekans & Yüzde \\
\hline \multirow{6}{*}{ Hanehalkı reisinin sigorta durumu } & İlköğretim veya ilkokul & 6.111 & 53.04 \\
\hline & Lise & 1.877 & 16.29 \\
\hline & Üniversite ve üzeri & 2.012 & 17.46 \\
\hline & Sigortasız & 484 & 4.24 \\
\hline & Genel sağlık sigortalı & 1.284 & 11.14 \\
\hline & Sigortalı & 9.748 & 84.61 \\
\hline \multirow{2}{*}{ Hanehalkı reisinin medeni durumu } & Bekâr & 2.446 & 21.23 \\
\hline & Evli & 9.075 & 78.77 \\
\hline \multirow{2}{*}{ Hanehalkı reisinin çalışma durumu } & Çalışıyor & 6.916 & 60.03 \\
\hline & Çalışmıyor & 4.605 & 39.97 \\
\hline \multirow{2}{*}{ Hanede $0-5$ yaş arası birey varlığ } & Yok & 8.860 & 76.90 \\
\hline & Var & 2.661 & 23.10 \\
\hline \multirow{2}{*}{ Hanede öğrenci varlığ1 } & Yok & 6.231 & 54.08 \\
\hline & Var & 5.290 & 45.92 \\
\hline \multirow{2}{*}{ Hanede 60 yaş ve üzeri birey varlığı } & Yok & 7.376 & 64.02 \\
\hline & Var & 4.145 & 35.98 \\
\hline \multirow{2}{*}{ Hanede alkol tüketme alışkanlığ 1} & Yok & 10.731 & 93.14 \\
\hline & Var & 790 & 6.86 \\
\hline \multirow{2}{*}{ Hanede sigara tüketme alışkanlığı } & Yok & 5575 & 48.39 \\
\hline & Var & 5946 & 51.61 \\
\hline \multirow{2}{*}{ Hanede ücretli spor alışkanlığı } & Yok & 10.685 & 92.74 \\
\hline & Var & 836 & 7.26 \\
\hline \multirow{2}{*}{ Kahvehaneye giden birey varlığı } & Yok & 8.281 & 71.88 \\
\hline & Var & 3.240 & 28.12 \\
\hline \multirow{2}{*}{ Özel sigorta varlığ 1} & Yok & 10.057 & 87.29 \\
\hline & Var & 1.464 & 12.71 \\
\hline \multirow{2}{*}{ Hanede kredi kartı varlığı } & Yok & 5.546 & 48.14 \\
\hline & Var & 5.975 & 51.86 \\
\hline \multirow{2}{*}{ Hanenin pazara gitme alışkanlığ } & Yok & 4.502 & 39.08 \\
\hline & Var & 7.019 & 60.92 \\
\hline \multirow{2}{*}{ Hanenin internetten alış veriş yapma alışkanlığı } & Yok & 9.917 & 86.08 \\
\hline & Var & 1.604 & 13.92 \\
\hline \multirow{2}{*}{ İnternet bağlantısı durumu } & Yok & 3.566 & 30.95 \\
\hline & Var & 7.955 & 69.05 \\
\hline \multirow{2}{*}{ Otomobil sahipliği } & Yok & 6.418 & 55.71 \\
\hline & Var & 5.103 & 44.29 \\
\hline \multirow{2}{*}{ İkinci konut sahipliği } & Yok & 10.468 & 90.86 \\
\hline & Var & 1.053 & 9.14 \\
\hline \multirow{4}{*}{ Hanehalkı tipi } & Tek başına yaşayan kişiler & 1224 & 10.62 \\
\hline & Çekirdek aile & 8634 & 74.94 \\
\hline & $\begin{array}{l}\text { Geniş aile (çekirdek aile ve diğer } \\
\text { kişilerden oluşan aile) }\end{array}$ & 1422 & 12.34 \\
\hline & $\begin{array}{l}\text { Bir arada yaşayan kişiler (aile } \\
\text { değil) }\end{array}$ & 241 & 2.09 \\
\hline \multirow{4}{*}{ Mülkiyet durumu } & Ev sahibi & 7093 & 61.57 \\
\hline & Kirac1 & 2578 & 22.38 \\
\hline & Lojman & 206 & 1.79 \\
\hline & $\begin{array}{l}\text { Ev sahibi değil fakat kira } \\
\text { ödemiyor (akraba evi, baba evi } \\
\text { vb.) }\end{array}$ & 1644 & 14.27 \\
\hline \multirow{2}{*}{ Hanenin toplu ulaşım araçlarına erişim kolaylığ } & Kolay & 8.842 & 76.75 \\
\hline & Zor & 2.679 & 23.25 \\
\hline \multirow{2}{*}{ Hanenin alış veriş hizmetlerine erişim kolaylığ } & Kolay & 9.091 & 78.91 \\
\hline & Zor & 2.430 & 21.09 \\
\hline Hanehalkı büyüklüğü (ortalama) & 3.36 kişi & & \\
\hline Hanehalkı yılllk geliri (ortalama) & $67.026,29 \mathrm{TL}$ & & \\
\hline
\end{tabular}




\subsection{Verilerin Analizi}

Hanelerin ev dışı gıda tüketip tüketmeme durumlarının belirlemek üzere kurulan YSA modelinde veri setinin \%70'i (8064 hane) YSA'nın eğitimi için kullanılırken kalan \%30'luk kısmı (3457 hane) test verisi olarak kullanılmıştır. Eğitim ve test verilerin seçimi, tüm veri seti içerisinden rassal olarak gerçekleştirilmiştir.

Sonuçların doğruluğunu ve güvenirliğini artırmak için çapraz doğrulama yöntemi kullanılarak hedef sınıflar tahmin edilmiştir. Modelde kullanılan k-katlı çapraz doğrulama yönteminde, veri seti rastgele $\mathrm{k}$ tane eşit büyüklükte alt kümeye ayrılır. Elde edilen $k$ adet alt kümeden, bir tanesi test ve geri kalan $k-1$ tanesi ise eğitim kümesi olarak kullanılır. Bu işlem k defa tekrarlandığında, $\mathrm{k}$ adet alt kümenin her biri test kümesi olarak bir defa kullanılır. Böylece tüm veri setinin hem eğitim hem de test kümesinde kullanılması sağlanmış olur (Açıkkar ve Sivrikaya, 2020, s. 19). Sonuçların ortalaması yöntemin doğruluğunu belirler (Kahramanli ve Allahverdi, 2008, s. 86). Uygulamalarda " $k$ " değeri için en uygun değerin 10 olduğu görülmüştür (Zhao ve Hasan, 2013, s. 67; Kaya, 2019, s. 586; Açıkkar ve Sivrikaya, 2020, s. 19). Gerçekleştirilen çalışmada k-katlı çapraz doğrulama yönteminde (X-Partitioner ve X-Aggregator) $k=10$ olarak alınarak sonuçların doğruluğu ve güvenirliğinin artırılması sağlanmıştır. Ayrıca, modelde Min-Max normalizasyon yöntemi kullanılarak veriler 0-1 aralığına indirgenmiştir (Jain vd., 2005, s. 2276). Çalışmaya ait akış şeması Şekil 2' de gösterilmiştir.
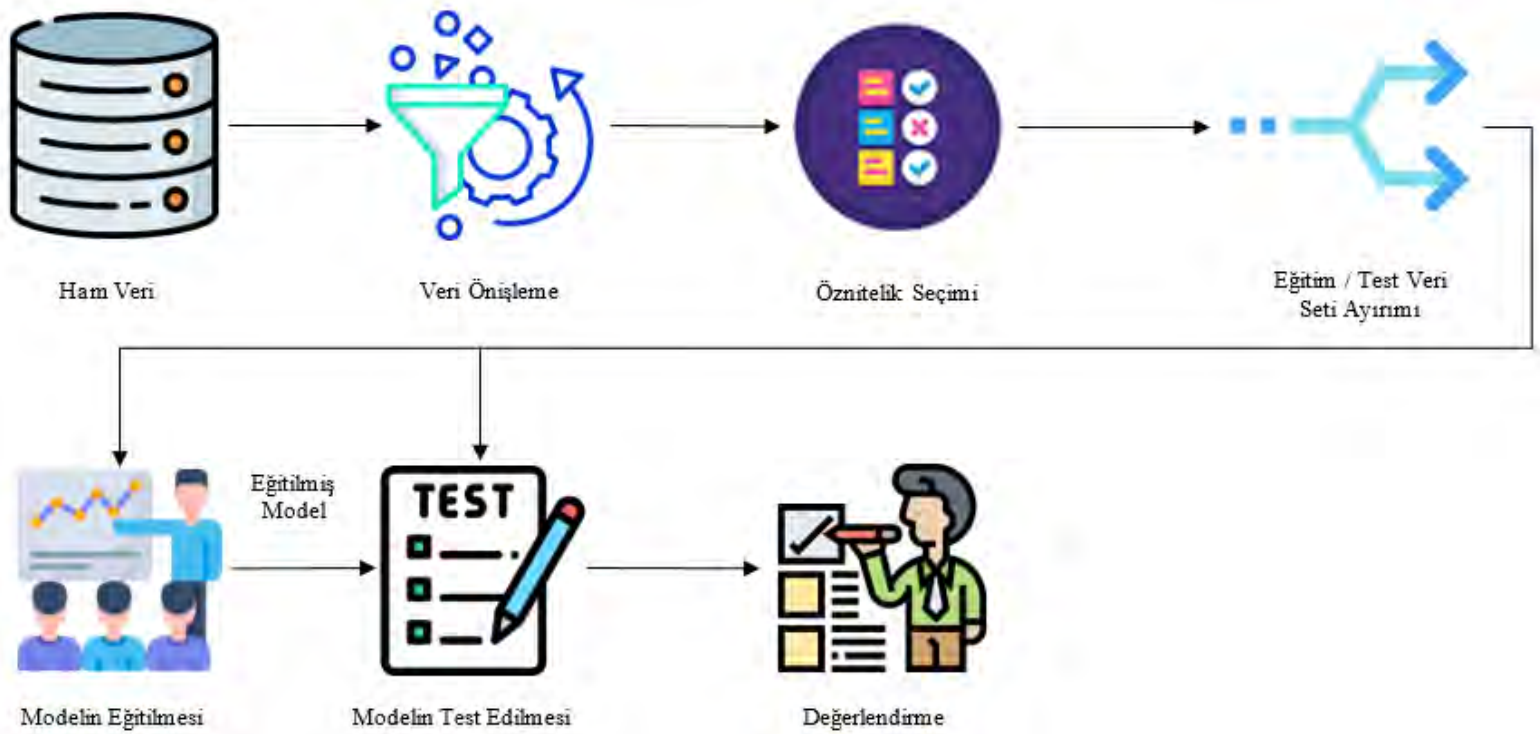

Şekil 2. Çalışmaya Ait Akış Şeması

Verilerin analizinde Knime Analytics Platform 4.3.3 programı kullanılmıştır. Knime platformunda oluşturulan YSA modeline ait tasarım Şekil 3'de gösterilmiştir.

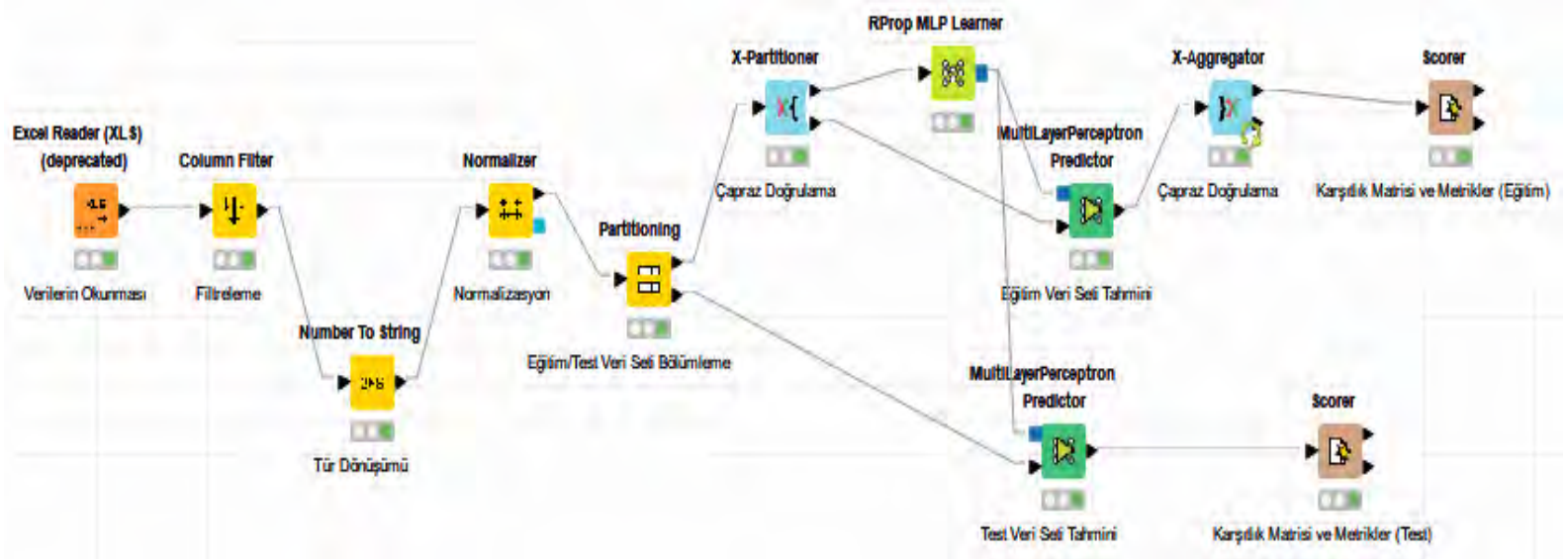

Şekil 3. Çalışmanın Knime Platformunda Uygulaması 
Bu çalışmada model olarak İleri Beslemeli YSA kullanılırken, öğrenme algoritması olarak geri yayılım algoritması kullanılmıştır. Tespit edilen en iyi modelin parametreleri; aktivasyon fonksiyonu olarak lojistik fonksiyon kullanılırken, 6 nöron, 2 gizli katman ve 5.000 iterasyon kullanılmıştır. Tek hedef değişken olduğu için bir çıkış nöronu bulunmaktadır. YSA modeline ait ağ topolojisi Şekil 4'de gösterilmiştir.

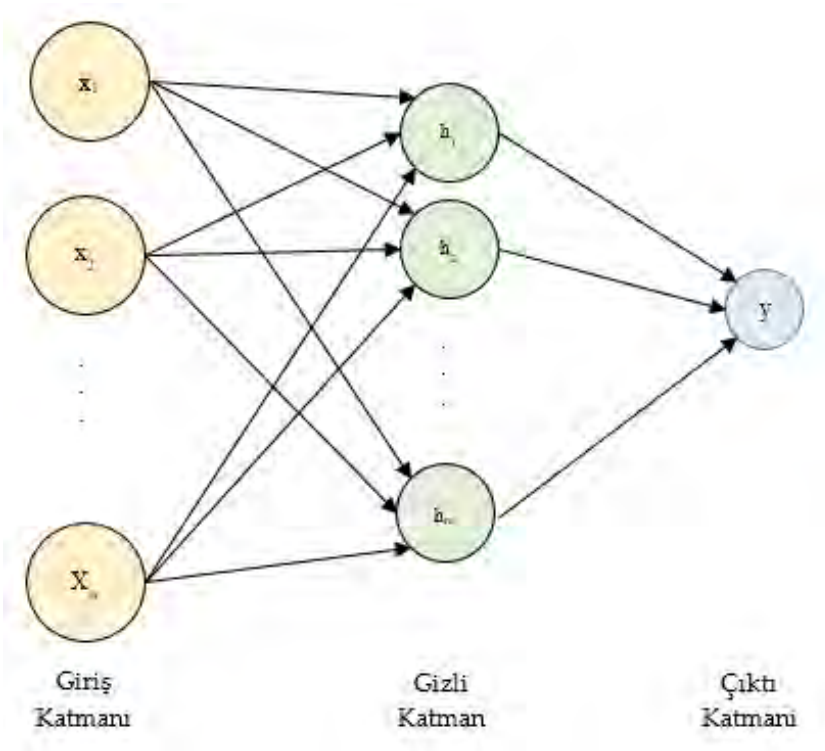

Şekil 4. A $\breve{g}$ Topolojisi

İki çıkış değerli (binary) sınıflandırma modellerinin değerlendirilmesinde kullanılan Karşıtlık Matrisi (Confusion Matrix) Tablo 2' de gösterilmiştir.

Tablo 2. İkili Sınıflar İçin Karşıtlık Matrisi

\begin{tabular}{llll} 
& & \multicolumn{2}{c}{ Tahmin Edilen Değer } \\
\cline { 3 - 4 } & & 0 (Yanlış) & 1 (Doğru) \\
\cline { 3 - 4 } Gerçek Değer & 0 (Yanlış) & DN (Doğru Negatif) & YP (Yanlış Pozitif) \\
\cline { 3 - 4 } & 1 (Doğru) & YN (Yanlış Negatif) & DP (Doğru Pozitif) \\
\hline
\end{tabular}

Karşıtlık Matrisine göre; gerçekte “ 0 ” olan bir değer “0” olarak tahmin edilirse DN (doğru negatif), gerçekte " 0 " olan bir değer " 1 " olarak tahmin edilirse YP (yanlış pozitif), gerçekte " 1 " olan bir değer " 1 " olarak tahmin edilirse DP (doğru pozitif), gerçekte "1" olan bir değer "0" olarak tahmin edilirse YN (yanlış negatif olarak) olarak etiketlenir.

YSA modelinin değerlendirilmesinde "doğruluk", “duyarlık”, “kesinlik”, “özgüllük”, “negatif tahmin oranı” ve "pozitif tahmin oranı" metrikleri kullanılmıştır. Tablo 2' deki veriler kullanılarak elde edilen bu metrikler sırasıyla Denklem 1-6'da gösterilmiştir (Chapi vd., 2017, s. 234-235; Luque vd., 2019, s. 218; Chen vd., 2020, s. 5; Ercan vd., 2020, s. 180-181; Zeng, 2020, s. 2088-2089).

Doğruluk $=\frac{D P+D N}{D P+D N+Y P+Y N}$
Duyarlık $=\frac{D P}{D P+Y N}$
Kesinlik $=\frac{D P}{D P+Y P}$
Özgüllük $=\frac{D N}{D N+Y P}$
Negatif Tahmin Oranı $=\frac{D N}{D N+Y N}$
Pozitif Tahmin Oranı $=\frac{D P}{D P+Y P}$ 


\section{Bulgular}

Hanenin ev dışı gıda tüketimi yapıp yapmadığını tahmin etmek için kurulan YSA modelinde eğitim sınıfı ve test sınıfı için elde edilen karşıtlık matrisleri Tablo 3'de gösterilmiştir.

Tablo 3. Eğitim ve Test Sınıfları İçin Karşıtlık Matrisi

\begin{tabular}{cccc|cc} 
& & \multicolumn{2}{c}{ Eğitim Veri Seti } & \multicolumn{2}{c}{ Test Veri Seti } \\
\cline { 3 - 5 } & & 0 & 1 & 0 & 1 \\
\cline { 3 - 5 } Gerçek Değer & 0 & 2791 & 1255 & 1180 & 589 \\
\cline { 3 - 5 } & 1 & 913 & 3105 & 331 & 1357 \\
\hline
\end{tabular}

YSA modelinin değerlendirilmesinde kullanılan doğruluk, duyarlık, kesinlik, özgüllük, negatif tahmin oranı ve pozitif tahmin oranına ait sonuçlar Tablo 4 ' de gösterilmiştir.

Tablo 4. Eğitim ve Test Sınıfları İçin Performans Metrikleri

\begin{tabular}{lcc}
\hline Metrik & Eğitim Değerleri & Test Değerleri \\
\hline Doğruluk & 0.7312 & 0.7339 \\
Duyarlık & 0.7728 & 0.8039 \\
Kesinlik & 0.7122 & 0.6973 \\
Özgüllük & 0.6898 & 0.6670 \\
Negatif tahmin oranı & 0.7535 & 0.7809 \\
Pozitif tahmin oranı & 0.7122 & 0.6973 \\
\hline
\end{tabular}

Veri setinde ev dışı gıda tüketimi yapan hane sayısı 5.706 (\%49.53), ev dışı gıda tüketimi yapmayan hane sayısı 5.815 'dir (\%50.47), elde edilen frekans ve yüzde değerlerine göre veri seti dengelidir. Eğitim ve test sınıfları için performans metriklerinin gösterildiği Tablo 4 incelendiği zaman, kurulan YSA modelinin başarısı Doğruluk değeri ile gösterilmektedir. Doğruluk değeri YSA sınıflandırıcısının toplam performansını değerlendirmede kullanılması açısından önemlidir. Doğruluk değerlerine göre YSA modeli eğitim aşamasında \%73.12, test aşamasında ise \%73.39 doğruluk performansı göstermiştir.

Ev dışı gıda tüketimi yapan hanelerin tahmininde pozitif yani ev dışı gıda tüketimi yapan/yapacak hanelerin tahmin edilmesinin daha önemli olduğu söylenebilir. Bu durumda Doğruluk değerinin yanında Kesinlik ve Duyarlılık değerlerinin de incelenmesi gereklidir. Duyarlılık ölçütü, toplam pozitif gözlemler içerisinde doğru tahmin edilen gözlemlerin oranını vermektedir. Gerçekte ev dışı gıda tüketimi yapan hanenin, test sonucunda da ev dışı gıda tüketimi yapan hane olarak etiketlenme olasılığını göstermesi açısından duyarlılık önemlidir. Gerçekte ev dışı gıda tüketimi yapmayan hanenin, test sonucunda da ev dışı gıda tüketimi yapmayan hane olarak etiketlenmesi olasılığını göstermesi açısından ise özgüllük önemlidir (Alan ve Karabatak, 2020, s. 535536). Duyarlık pozitif sınıf açısından, özgüllük negatif sınıf açısından değerlendirilmektedir (Japkowicz ve Shah, 2011, s. 96). Modelleme sonucu, gerçekte ev dişı gıda tüketimi yapan hanelerin model tarafından doğru tahmin edilme oranı eğitim veri setinde \%77.28 iken test veri setinde \%80.39 olarak elde edilmiştir. Model tarafından ev dışı gıda tüketimi yapmayan haneler eğitim veri setinde $\% 68.98$, test veri setinde ise $\% 66.70$ ile doğru tahmin edilmiştir. Kesinlik ve pozitif tahmin oranı aynı formülasyonla elde edilmesinden dolayı aynı sonuçları vermektedir. Kesinlik (pozitif tahmin oranı) toplam pozitif tahminler içerisinde doğru pozitif tahminlerini oranını vermektedir. Gerçekleştirilen çalışmada kesinlik değeri, doğru şekilde etiketlenmiş ev dışı gıda tüketimi yapan hanelerin oranını ölçer. Modelin kesinliği test aşamasında \%71.22 iken test aşamasında ise \%69.73'dür. Benzer şekilde negatif tahmin oranı ise, doğru şekilde etiketlenmiş ev dışı gıda tüketimi yapmayan hane oranını ölçmektedir. Dolayısıyla iyi bir sınıflandırıcıdan elde edilen hem pozitif hem de negatif tahmin oranlarının yüksek olması beklenir. Tablo 3'de gösterilen karşıtlık matrislerinden elde edilen ve Tablo 4'de belirtilen metriklere bakıldığı zaman, eğitim ve test aşamasındaki sonuçların birbirine yakın olduğu görülmektedir. Bu sonuçlara göre kurulan modelin tutarlı olduğu söylenebilir.

\section{Sonuç ve Tartışma}

Gelirde meydana gelen değişimler, kentleşme ve küreselleşme, kadınların iş gücüne katılımı gibi nedenlerden dolayı insanların tüketim kalıpları ve tüketici davranışları değişmiş bununla beraber ev dışı gıda tüketimi artmıştır (Gül vd., 2007, s. 32; Smith vd., 2014, s. 20; Farfán vd., 2017, s. 146). Ev dışı gıda tüketiminin artması, 
ev dışı gıda tüketimini etkileyen değişkenlerin belirlenmesini önemli kılmıştır. Gerek bireysel gerekse hanehalkı ev dışı gıda tüketimini etkileyen faktörleri belirlemek adına birçok ekonometrik model kurulmuş, analiz edilerek yorumlanmıştır. Bu çalışmada hanehalkı ev dişı gıda tüketim durumunun (tüketip tüketmeme) tahmin edilmesine yönelik ekonometrik yöntemlerden farklı olarak problem bir sinıflama problemi olarak ele alınmış ve veri madenciliği süreçlerinde modelleme yöntemlerinden biri olan YSA metodu modelleme aşamasında kullanılmıştır.

Hanehalkı ev dışı gıda tüketim sınıfını tahmin etmek için oluşturulan YSA modelinde, hanehalkının ev dışı gıda tüketme durumu çıkış, hanehalkı ve fert karakteristikleri ise giriş değişkeni olarak kullanılmıştır. YSA modelinin sonucuna göre, eğitim aşamasında \%73.12, test aşamasında ise \%73.39 doğru tahmin yüzdesi elde edilmiştir. Modelin duyarlığı eğitim aşamasında \%77.28 test aşamasında ise $\% 80.39$ 'dir. Modelin kesinliği test aşamasında \%71.22 test aşamasında ise \%69.73'dür. YSA modelinin ürettiği eğitim ve test aşaması sonuçlarından elde edilen metrikler incelendiğinde sistemin doğru ve tutarlı sonuçlar elde ettiği görülmüştür.

Literatür incelendiğinde YSA yöntemi ile Türkiye hanehalkı ev dışı gıda tüketim sınıflarının tahmin edilmesine yönelik bir çalışmaya rastlanılmamıştır. Bu nedenden dolayı gerçekleştirilen çalışmanın literatüre özgün bir katkı yapacağı düşünülmektedir. Buna ek olarak daha önceki yıllara ait veriler kullanılarak kurulan modellerden elde edilen sonuçlar karşılaştırılarak yıllar içerisinde meydana gelen değişmeler gözlemlenebilir. Ayrıca, sınıflandırma amacıyla kullanılan Rastgele Orman, Destek Vektör Makineleri gibi diğer yöntemler kullanılarak elde edilen sonuçlar ile YSA modelinin başarıları ve etkinlikleri karşılaştırılabilir. Çalışmadan elde edilen bulgular, ev dışı gıda sektörünün gıda tedarik, hazırlama, dağıtım, reklam ve pazarlama alanlarında faaliyet gösteren firmalara planlama yapma, karar verme alanlarında katkısı olacağı düşünülmektedir. Literatürde incelenen çalışmalardan elde edilen değişkenlerin haricinde modele eklenen değişkenlerin, kurulan Yapay Sinir Ağları modelinin sınıflandırma doğruluğunu arttırdığı görülmüştür. Elde edilen bulgular doğrultusunda literatürden bağımsız olarak eklenen değişkenler, logit/probit regresyon gibi istatistiksel ve ekonometrik metotlarla yapılacak çalışmalara bağımsız değişken olarak eklenebilir. Eklenen bu değişkenlerin kurulan modellerin sonuçlarını ve yapısını değiştirebileceği düşünülmektedir.

\section{Kaynakça}

Açıkkar, M. ve Sivrikaya, O. (2020). Yıkanmış Türk Linyit Kömürlerinin Üst Isıl Değerinin Destek Vektör Regresyonu ile Tahmini. Avrupa Bilim ve Teknoloji Dergisi, 18, 16-24.

Adams, J., Goffe, L., Brown, T., Lake, A. A., Summerbell, C., White, M., Wrieden, W. and Adamson, A. J. (2015). Frequency and Socio-Demographic Correlates of Eating Meals Out And Take-Away Meals at Home: Cross-Sectional Analysis of The UK National Diet and Nutrition Survey, Waves 1-4 (2008-12). International Journal of Behavioral Nutrition and Physical Activity, 12(1), 1-9.

Akbay, C. ve Boz, İ. (2005). Kahramanmaraş'ta Ailelerin Ev ve Ev Dışı Gıda Tüketim Talebi ve Tüketici Davranışlarının Ekonomik Analizi. KSÜ Fen ve Mühendislik Dergisi, 8(1), 122-131.

Akpınar, H. (2000). Veri Tabanlarında Bilgi Keşfi ve Veri Madenciliği. ï̈̈ Isşletme Fakültesi Dergisi, 29(1), 1-22.

Alan, A. ve Karabatak, M. (2020). Veri Seti-Sınıflandırma İlişkisinde Performansa Etki Eden Faktörlerin Değerlendirilmesi. Fırat Üniversitesi Mühendislik Bilimleri Dergisi, 32(2), 531-540.

Andrade, G. C., da Costa Louzada, M. L., Azeredo, C. M., Ricardo, C. Z., Martins, A. P. B. and Levy, R. B. (2018), Out-of-Home Food Consumers in Brazil: What Do They Eat?. Nutrients, 10, 218, 1-12.

Ayık, Y. Z., Özdemir, A., \& Yavuz, U. (2007). Lise Türü Ve Lise Mezuniyet Başarısının, Kazanılan Fakülte İle İlişkisinin Veri Madenciliğgi Tekniği İle Analizi. Atatürk Üniversitesi Sosyal Bilimler Enstitüsü Dergisi, 10(2), $441-454$.

Bamiro, O. M. (2012). Determinants of Consumption of Food Away From Home in Lagos Metropolis, Nigeria. Research Journal of Social Sciences and Management, 2(5), 15-23. 
Berry, M. J. A. and Linoff, G. S. (2004). Data Mining Techniques For Marketing, Sales, and Customer Relationship Management (Second Edition). Indianapolis, Indiana: Wiley Publishing Inc.

Chapi, K., Singh, V. P., Shirzadi, A., Shahabi, H., Bui, D. T., Pham, B. T. and Khosravi, K. (2017). A Novel Hybrid Artificial Intelligence Approach For Flood Susceptibility Assessment. Environmental Modelling \& Software, 95, 229-245.

Chen, W., Li, Y., Xue, W., Shahabi, H., Li, S., Hong, H., Wang, X., Bian, H., Zhang, S., Pradhan, B. and Ahmad, B. B. (2020). Modeling Flood Susceptibility Using Data-Driven Approaches of Naïve Bayes Tree, Alternating Decision Tree, and Random Forest Methods. Science of The Total Environment, 701, 1-11.

Çalmaşur, G. ve Daştan, H. (2020). Erzurum İlinde Hanehalklarının Ev Dışı Gıda Tüketimini Etkileyen Faktörler. Uluslararası İktisadi ve İdari Bilimler Dergisi, 6(1), 97-111.

Demirel, O., ve Hatırlı, S. A. (2020). Türkiye'de Ev-Dışı Yemek Yeme Alışkanlığının Analizi. Uluslararası Yönetim İktisat ve İşletme Dergisi, 16(4), 976-988.

Dong, D., Byrne, P. J., Saha, A. and Capps Jr., O. (2000). Determinants of Food-Away-From-Home (FAFH) Visit Frequency: A Count-Data Approach. Journal of Restaurant \& Foodservice Marketing, 4(1), 31-46.

Drescher, L. S. and Roosen, J. (2013). A Cohort Analysis of Food-at-Home and Food-Away-From-Home Expenditures in Germany. German Journal of Agricultural Economics, 62(1), 39-51.

Ercan, U., Irmak, S., Çevik, K. K. ve Canbazoğlu, E. (2020). Yapay Sinir Ağları Kullanılarak Konutlarda Elektrik Tüketimi Düzeylerinin Tahmin Edilmesi. Sosyoekonomi, 28(46), 173-186.

Fabiosa J. F. (2008). The Food Away From Home Consumption Expenditure Pattern in Egypt. CARD Working Papers, 503, Working Paper 08-WP 474. http://lib.dr.iastate.edu/card_workingpapers/503.

Fanning, J., Marsh, T. and Stiegert, K. (2010). Determinants of US Fast Food Consumption 1994-1998. British Food Journal, 112(1), 5-20.

Farfán, G., Genoni, M. E. and Vakis, R. (2017). You Are What (and Where) You Eat: Capturing Food Away From Home in Welfare Measures. Food Policy, 72: 146-156.

Fausett, L. (1994). Fundamentals of Neural Networks: Architectures, Algorithms and Applications. Englewood Cliffs, NJ: Prentice-Hall.

Giudici, P. (2003). Applied Data Mining Statistical Methods for Business and Industry. West Sussex, England: John Wiley \& Sons.

Gönül, S. ve Karlı, B. (2020). Antalya İlinde Hanehalklarının Ev Dışı Gıda Tüketimi ve Tüketici Eğilimleri. Mustafa Kemal Üniversitesi Tarım Bilimleri Dergisi, 25(1), 10-19.

Gül, A., Akbay, C., Özcicek, C., Özel, R. and Akbay, A. O. (2007). Expenditure Pattern For Food Away From Home Consumption in Turkey. Journal of International Food \& Agribusiness Marketing, 19(4), 31-43.

Han, J., Kamber, M. and Pei, J. (2011). Data Mining Concepts and Techniques Third Edition. The Morgan Kaufmann Series In Data Management Systems. USA, Waltham: Elsevier.

Haykin, S. (2008). Neural Networks and Learning Machines Third Edition. New Jersey: Pearson, Prentice Hall.

Irmak, S. (2009). Veri Madenciliği Yöntemleri İle Sağlık Sektörü Veritabanlarında Bilgi Keşfi: Tanımlayıcı ve Kestirimci Model Uygulamaları. (Yayımlanmamış Doktora Tezi). Akdeniz Üniversitesi Sosyal Bilimler Enstitüsü, Antalya.

Jain, A., Nandakumar, K. and Ross, A. (2005). Score Normalization in Multimodal Biometric Systems. Pattern Recognition, 38, 2270-2285.

Janssen, H. G., Davies, I. G., Richardson, L. D. and Stevenson, L. (2018). Determinants of Takeaway and Fast Food Consumption: A Narrative Review. Nutrition Research Reviews, 31, 16-34. 
Japkowicz, N. and Shah, M. (2011). Evaluating Learning Algorithms A Classification Perspective. USA, New York: Cambridge University Press.

Kahramanli, H. and Allahverdi, N. (2008). Design of a Hybrid System for The Diabetes and Heart Diseases. Expert Systems with Applications, 35, 82-89.

Kant, A. K., Whitley, M. I. and Graubard, B. I. (2015). Away From Home Meals: Associations With Biomarkers of Chronic Disease and Dietary Intake in American Adults, NHANES 2005-2010. International Journal of Obesity, 39, 820-827.

Kantardzic, M. (2019). Data Mining Concepts, Models, Methods, and Algorithms Third Edition. New Jersey: John Wiley \& Sons, Inc.

Kaya, D. (2019). Alt Uzay k-NN ile Eritmato-Skuamöz Hastalık Türlerinin Sınıflandırılması. Fırat Üniversitesi Mühendislik Bilimleri Dergisi, 31(2), 583-587.

Kutluay Tutar, F. ve Yazırlı, N. (2016). Hanehalkı Ev Dışı Gıda Tüketimini Etkileyen Faktörler: Nazilli Örneği. Çankırı Karatekin Üniversitesi Sosyal Bilimler Enstitüsü Dergisi, 7(1), 367-392.

Larose, D. T. (2005). Discovering Knowledge in Data an Introduction to Data Mining, New Jersey: John Wiley \& Sons, Inc.

Lavrač, N. and Zupan, B. (2010). Data Mining in Medicine. Maimon, O. and Rokach, L. (Ed.), Data Mining and Knowledge Discovery Handbook Second Edition, New York: Springer, 1111-1136.

Liu, H., Wahl, T. I., Seale Jr, J. L. and Bai, J. (2015). Household Composition, Income, and Food-Away-FromHome Expenditure in Urban China. Food Policy, 51, 97-103.

Luque, A., Carrasco, A., Martín, A. and de las Heras, A. (2019). The Impact of Class Imbalance in Classification Performance Metrics Based on The Binary Confusion Matrix. Pattern Recognition, 91, 216-231.

Ma, H., Huang, J., Fuller, F. and Rozelle, S. (2006). Getting Rich and Eating Out: Consumption of Food Away From Home in Urban China. Canadian Journal of Agricultural Economics/Revue canadienne d'agroeconomie, $54,101-119$.

Mottaleb, K. A., Rahut, D. B. and Mishra, A. K. (2017). Consumption of Food Away From Home in Bangladesh: Do Rich Households Spend More?. Appetite, 119, 54-63.

Saksena, M. J., Okrent, A. M., Anekwe, T. D., Cho, C., Dicken, C., Effland, A., Elitzak, H., Guthrie, J., Hamrick, K. S., Hyman, J., Jo, Y., Lin, B. H., Mancino, L., McLaughlin, P. W., Rahkovsky, I., Ralston, K., Smith, T. A., Stewart, H., Todd, J. and Tuttle, C. (2018). America's Eating Habits: Food Away From Home (No. 281119). United States Department of Agriculture, Economic Research Service, Economic Information Bulletin Number 196.

Skias, S. T. (2006). Background of the Verification And Validation of Neural Networks. Taylor, B. J. (Ed.), Methods and Procedures for the Verification and Validation of Artificial Neural Networks, USA, New York: Springer, 1-12.

Smith, L.C., Dupriez, O. and Troubat, N. (2014). Assessment of the Reliability and Relevance of the Food Data Collected in National Household Consumption and Expenditure Surveys. International Household Survey Network. IHSN Working Paper Number 8.

TÜIK (2019). Türkiye İstatistik Kurumu, Hanehalkı Bütçe Anketi 2019, Ankara.

Yakut, E., Gündüz, M. ve Demirci, A. (2015). İnsani Kalkınmışlık Düzeyinin Sınıflandırma Başarılarının Karşılaştırılmasında Sıralı Lojistik Regresyon Analizi ve Yapay Sinir Ağları Yöntemlerinin Kullanılması. İşletme Araştırmaları Dergisi, 7(4), 172-199.

Yücesan, M. (2018). YSA, ARIMA ve ARIMAX Yöntemleriyle Satış Tahmini: Beyaz Eşya Sektöründe bir Uygulama. İşletme Araştırmaları Dergisi, 10(1), 689-706. 
Zang, J., Luo, B., Wang, Y., Zhu, Z., Wang, Z., He, X., Wang, W., Guo, Y., Chen, X., Wang, C., Guo, C., Zou, S., Jia, X. and Wu, F. (2018). Eating Out-of-Home in Adult Residents in Shanghai and the Nutritional Differences Among Dining Places. Nutrients, 10, 951, 1-13.

Zeng, G. (2020). On The Confusion Matrix in Credit Scoring and Its Analytical Properties. Communications in Statistics-Theory and Methods, 49(9), 2080-2093.

Zhang, G. P. (2010). Neural Networks for Data Mining. Maimon, O. and Rokach, L. (Ed.), Data Mining and Knowledge Discovery Handbook Second Edition, New York: Springer, 419-444.

Zhao, Y. and Hasan, Y. A. (2013). Machine Learning Algorithms for Predicting Roadside Fine Particulate Matter Concentration Level in Hong Kong Central. Computational Ecology and Software, 3(3), 61-73. 